\title{
Wave spectral shapes in the coastal waters based on measured data off Karwar on the western coast of India
}

\author{
M. Anjali Nair and V. Sanil Kumar \\ Ocean Engineering Division, Council of Scientific \& Industrial Research-National Institute of Oceanography, Dona Paula, \\ 403004 Goa, India
}

Correspondence to: V. Sanil Kumar (sanil@nio.org)

Received: 29 November 2016 - Discussion started: 6 January 2017

Revised: 10 April 2017 - Accepted: 12 April 2017 - Published: 3 May 2017

\begin{abstract}
An understanding of the wave spectral shapes is of primary importance for the design of marine facilities. In this paper, the wave spectra collected from January 2011 to December 2015 in the coastal waters of the eastern Arabian Sea using the moored directional waverider buoy are examined to determine the temporal variations in the wave spectral shape. Over an annual cycle for $31.15 \%$ of the time, the peak frequency is between 0.08 and $0.10 \mathrm{~Hz}$; the significant wave height is also relatively high $(\sim 1.55 \mathrm{~m})$ for waves in this class. The slope of the high-frequency tail of the monthly average wave spectra is high during the Indian summer monsoon period (June-September) compared to other months, and it increases with an increase in significant wave height. There is not much interannual variation in the slope for swell-dominated spectra during the monsoon, while in the non-monsoon period when wind-seas have a high level of influence, the slope varies significantly. Since the exponent of the high-frequency part of the wave spectrum is within the range of -4 to -3 during the monsoon period, the Donelan spectrum shows a better fit for the high-frequency part of the wave spectra in monsoon months compared to other months.
\end{abstract}

\section{Introduction}

Information on wave spectral shapes is required for designing marine structures (Chakrabarti, 2005), and almost all of the wave parameter computations are based on the wave spectral function (Yuan and Huang, 2012). The growth of waves and the corresponding spectral shape is due to the complex ocean-atmosphere interactions, while the physics of the air-sea interaction is not completely understood (Cav- aleri et al., 2012). The shape of the wave spectrum depends on the factors governing the wave growth and decay, and a number of spectral shapes have been proposed in the past for different sea states (see Chakrabarti, 2005 for a review). The spectral shape is maintained by the nonlinear transfer of energy through nonlinear four-wave interactions (quadruplet interactions) and whitecapping (Gunson and Symonds, 2014). The momentum flux between the ocean and the atmosphere govern the high-frequency wave components (Cavaleri et al., 2012). According to Phillips (1985) the equilibrium ranges for low-frequency and high-frequency regions are proportional to $f^{-5}$ and $f^{-4}$ (where $f$ is the frequency), respectively. Several field studies conducted since the JONSWAP (Joint North Sea Wave Project) field campaign reveal an analytical form for wave spectra with the spectral tail proportional to $f^{-4}$ (Toba, 1973; Kawai et al., 1977; Kahma, 1981; Forristall, 1981; Donelan et al., 1985). Usually, there is a predominance of swell fields in large oceanic areas, which is due to remote storms (Chen et al., 2002; Hwang et al., 2011; Semedo et al., 2011). The exponent used in the expression for the frequency tail has different values (see Siadatmousavi et al., 2012 for a brief review). For shallow water, Kitaigordskii et al. (1975) suggested an $f^{-3}$ tail and Liu et al. (1989) suggested $f^{-4}$ for growing young wind-seas and $f^{-3}$ for fully developed wave spectra. Badulin et al. (2007) suggested $f^{-4}$ for frequencies with dominant nonlinear interactions. The study carried out at Lake George by Young and Babanin (2006) revealed that in the frequency range $5 f_{\mathrm{p}}<f<10 f_{\mathrm{p}}$, the average value of the exponent " $n$ " of $f^{-n}$ is close to 4 . Other studies in real sea conditions indicate that the high-frequency shape of $f^{-4}$ applies up to a few times the peak frequency $\left(f_{\mathrm{p}}\right)$ and then decays faster with fre- 
quency. The spectra for coastlines in Currituck Sound with short fetch conditions showed a decay closer to $f^{-5}$ when $f$ is greater than 2 or 3 times the peak frequency (Long and Resio, 2007). Gagnaire-Renou et al. (2010) found that the energy input from wind and the dissipation due to whitecapping have a significant influence on the high-frequency tail of the spectrum.

The physical processes in the northern Indian Ocean have a distinct seasonal cycle (Shetye et al., 1985; Ranjha et al., 2015), and the surface wind-wave field is no exception (Sanil Kumar et al., 2012). In the eastern Arabian Sea (AS), the significant wave height $\left(H_{\mathrm{m} 0}\right)$ up to $6 \mathrm{~m}$ is measured in the monsoon period (June to September). During the rest of the periods, $H_{\mathrm{m} 0}$ is normally less than $1.5 \mathrm{~m}$ (Sanil Kumar and Anand, 2004). Sanil Kumar et al. (2014) observed that in the eastern AS, the wave spectral shapes are different at two locations within a $350 \mathrm{~km}$ distance, even though the difference in the integrated parameters like $H_{\mathrm{m} 0}$ is marginal. Dora and Sanil Kumar (2015) observed that waves at $7 \mathrm{~m}$ of water depth in the nearshore zone off Karwar are highenergy waves in the monsoon period and low to moderate waves in the non-monsoon period (January to May and October to December). The Dora and Sanil Kumar (2015) study shows a similar contribution of wind-seas and swells during the pre-monsoon period (February to May), while swells dominate the wind-sea in the post-monsoon period (October to January) and the monsoon period. A study was carried out by Glejin et al. (2012) to find the variation in wave characteristics along the eastern AS and the influence of swells in the nearshore waves at three locations during the monsoon period in 2010 . This study shows that the percentage of swells in the measured waves was $75 \%$ at the southern part of the AS and $79 \%$ at the northern part of the AS. Wind and wave data measured at a few locations along the western coast of India for a short period of 1 to 2 months as well as the wave model results were analyzed to study the wave characteristics in the deep and nearshore regions during different seasons (Vethamony et al., 2013). From the wave data collected for a 2-year period (2011 and 2012) along the eastern AS, swells of more than $18 \mathrm{~s}$ and significant wave heights of less than $1 \mathrm{~m}$, which occur 1.4 to $3.6 \%$ of the time, were separated and their characteristics were studied by Glejin et al. (2016). Anjali Nair and Sanil Kumar (2016) presented the daily, monthly, seasonal and annual variations in the wave spectral characteristics for a location in the eastern AS and reported that over an annual cycle, $29 \%$ of the wave spectra are single-peaked spectra and $71 \%$ are multi-peaked spectra. Recently, Amrutha et al. (2017) analyzed the measured wave data in October and reported that the high waves (significant wave height $>4 \mathrm{~m}$ ) generated in an area bounded by $40-60^{\circ} \mathrm{S}$ and $20-40^{\circ} \mathrm{E}$ in the southern Indian Ocean reached the eastern AS in 5-6 days and resulted in the long-period waves. Earlier studies indicate that the spectral tail of the high-frequency part shows large variation and that its variation with seasons is not known. Similarly, the shape of the parametric spectra are also different, and hence it is important to identify the spectral shapes based on the measured data covering all seasons and different years.

The discussion above shows that there is a strong motivation to study the high-frequency tail of the wave spectrum. For the present study, we used the directional waverider buoy with measured wave spectral data at $15 \mathrm{~m}$ of water depth off Karwar on the western coast of India over 5 years from 2011 to 2015 and evaluated the nearshore wave spectral shapes in different months. This study addresses two main issues: (1) how the high-frequency tail of the wave spectrum varies in different months and (2) the spectral parameters for the best-fit theoretical spectra. This paper is organized as follows: the study area is introduced in Sect. 2, and the details of data used and the methodology are presented in Sect. 3. Section 4 presents the results of the study, and the conclusions are given in Sect. 5.

\section{Study area}

The coastline at Karwar is $24^{\circ}$ inclined to the west from the north, and the $20 \mathrm{~m}$ depth contour is inclined $29^{\circ}$ to the west. Hence, large waves in the nearshore will have an incoming direction close to $241^{\circ}$, since waves become aligned with the depth contour due to refraction. At 10, 30 and $75 \mathrm{~km}$ of distance from Karwar, depth contours are present at 20,50 and $100 \mathrm{~m}$ (Fig. 1). The study region is under the seasonally reversing monsoon winds, with winds from the northeast during the post-monsoon period and from the southwest during the monsoon period. The monsoon winds are strong, and the total seasonal rainfall is $280 \mathrm{~cm}$. There is a $0.24 \mathrm{~m}$ annual cycle in the mean sea level from September to January. The average tidal range is $1.58 \mathrm{~m}$ during spring tides and $0.72 \mathrm{~m}$ during neap tides (Sanil Kumar et al., 2012).

\section{Data and methods}

The waves off Karwar $\left(14^{\circ} 49^{\prime} 56^{\prime \prime} \mathrm{N}\right.$ and $\left.74^{\circ} 6^{\prime} 4^{\prime \prime} \mathrm{E}\right)$ were measured using the directional waverider buoy (DWRMKIII) . The measurements were carried out from 1 January 2011 to 31 December 2015. The heave data and the two-translational motion of the buoy are sampled at $3.84 \mathrm{~Hz}$. A digital high-pass filter with a cutoff at $30 \mathrm{~s}$ is applied to the $3.84 \mathrm{~Hz}$ samples. At the same time, it converts the sampling rate to $1.28 \mathrm{~Hz}$ and stores the time series data at $1.28 \mathrm{~Hz}$. From the time series data for $200 \mathrm{~s}$, the wave spectrum is obtained through a fast Fourier transform (FFT). During half an hour, eight wave spectra with a $200 \mathrm{~s}$ data interval are collected and averaged to get a representative wave spectrum for half an hour (Datawell, 2009). The wave spectrum has a resolution of $0.005 \mathrm{~Hz}$ from 0.025 to $0.1 \mathrm{~Hz}$ and $0.01 \mathrm{~Hz}$ from 0.1 to $0.58 \mathrm{~Hz}$. The bulk wave parameters are the significant wave height $\left(H_{\mathrm{m} 0}\right)$, which equals $4 \sqrt{m_{0}}$, and the mean wave period $\left(T_{\mathrm{m} 02}\right)$ based on second-order moment, 


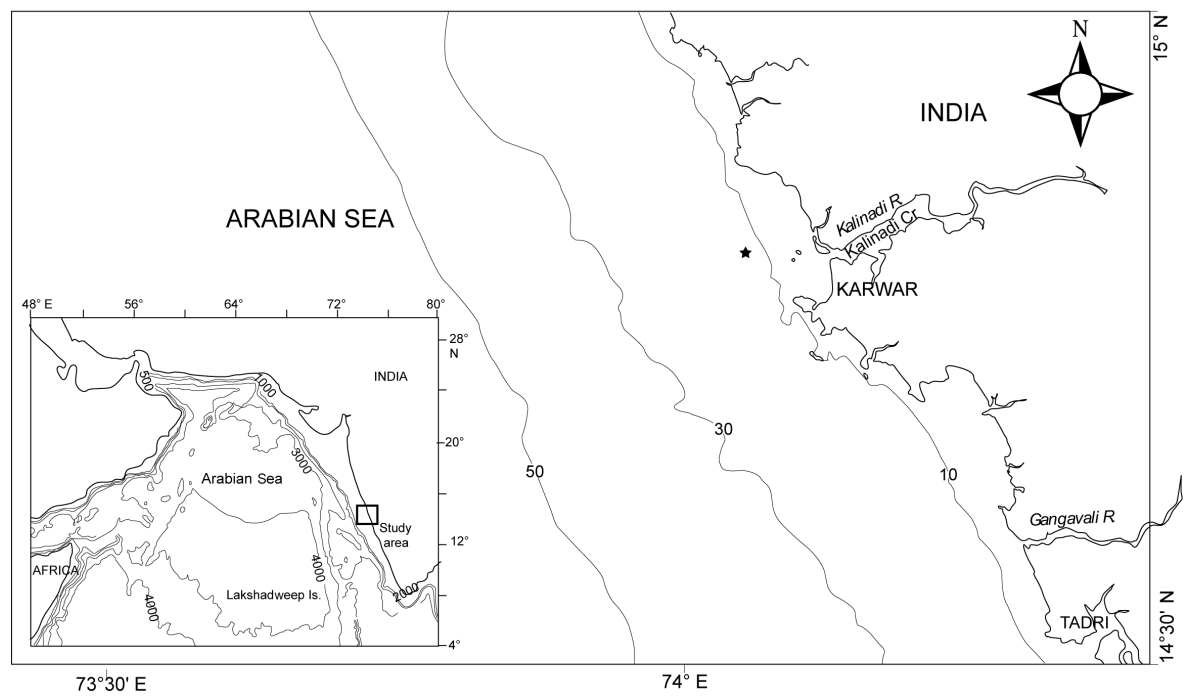

Figure 1. The study area along with the wave measurement location in the eastern Arabian Sea.

which equals $\sqrt{m_{0} / m_{2}}$ ); these are obtained from the spectral moments where $m_{n}$ is the $n$ th-order spectral moment $\left(m_{n}=\int_{0}^{\infty} f^{n} S(f) d f, n=0\right.$ and 2$), S(f)$ is the spectral energy density and $f$ is the frequency. The spectral peak period $\left(T_{\mathrm{p}}\right)$ is estimated from the wave spectrum, and the peak wave direction $\left(D_{\mathrm{p}}\right)$ is estimated based on circular moments (Kuik et al., 1988). The wind-seas and swells are separated through the method described by Portilla et al. (2009), and the wind-sea and the swell parameters are computed by integrating over the respective spectral parts. The measurements reported here are in Coordinated Universal Time (UTC), which is $5 \mathrm{~h} 30 \mathrm{~min}$ behind the local time. $U_{10}$ is the wind speed at $10 \mathrm{~m}$ of height obtained from the reanalysis data of the zonal and meridional components at 6-hourly intervals from NCEP/NCAR (Kalnay et al., 1996). It is used to study the influence of wind speed on the spectral shape.

Since the frequency bins over which the wave spectrum is estimated are the same in all years, the monthly and seasonally averaged wave spectrum is computed by taking the average of the spectral energy density at the respective frequencies of each spectrum over the specified time.

The wave spectrum continues to develop through nonlinear wave-wave interactions, even for very long times and distances. Hence, most of the wave spectrum is not fully developed and cannot be represented by the PiersonMoskowitz (PM) spectrum (Pierson and Moskowitz, 1964). Accordingly, an additional factor was added to the PM spectrum in order to improve the fit to the measured spectrum. The JONSWAP spectrum (Hasselmann et al., 1973) is thus a PM spectrum multiplied by an extra peak enhancement factor $\gamma$. The high-frequency tail of the JONSWAP spectrum decays in a form proportional to $f^{-5}$. A number of studies reported that high-frequency decay is by a form propor- tional to $f^{-4}$. A modified JONSWAP spectrum that includes Toba's formulation of the saturation range was proposed by Donelan et al. (1985). The JONSWAP and Donelan spectra used in the study are given in Eqs. (1) and (2):

$$
\begin{aligned}
& S(f)=\frac{\alpha g^{2}}{(2 \pi)^{4} f^{5}} \exp \left[-\frac{5}{4}\left(\frac{f}{f_{\mathrm{p}}}\right)^{-4}\right] \gamma^{\exp \left[-\left(f-f_{\mathrm{p}}\right)^{2} / 2 \sigma^{2} f_{\mathrm{p}}\right],} \\
& S(f)=\frac{\alpha g^{2}}{(2 \pi)^{4} f^{4}} f_{\mathrm{p}} \exp \left[-\left(\frac{f}{f_{\mathrm{p}}}\right)^{-4}\right] \gamma^{\exp \left[-\left(f-f_{\mathrm{p}}\right)^{2} / 2 \sigma^{2} f_{\mathrm{p}}^{2}\right] .}
\end{aligned}
$$

Here, $\gamma$ is the peak enhancement parameter, $\alpha$ is the Phillips constant, $f$ is the wave frequency, $g$ is the gravitational acceleration and $\sigma$ is the width parameter:

$\sigma=\left\{\begin{array}{ll}0.07, & f<f_{\mathrm{p}} \\ 0.09, & f \geq f_{\mathrm{p}}\end{array}\right\}$.

An exponential curve $y=k f^{b}$ is fitted for the highfrequency part of the spectrum and the exponent (the value of $b$ ) and the coefficient $k$ are estimated for the best-fitting curve based on statistical measures such as the least-squares error and the bias. The slope of the high-frequency part of the wave spectrum is represented by the exponent of the highfrequency tail.

For the present study, the JONSWAP spectrum is tested by fitting for the whole frequency range of the measured wave spectrum. It is found out that the JONSWAP spectra do not show a good fit for higher-frequency ranges, whereas the Donelan spectrum shows a better fit for the high-frequency range. Hence, the JONSWAP spectrum is used for the lowerfrequency range up to the spectral peak, and the Donelan spectrum is used for the higher-frequency range from the spectral peak for the single-peaked wave spectrum. The theoretical wave spectra are not fitted to the double-peaked wave spectra. 

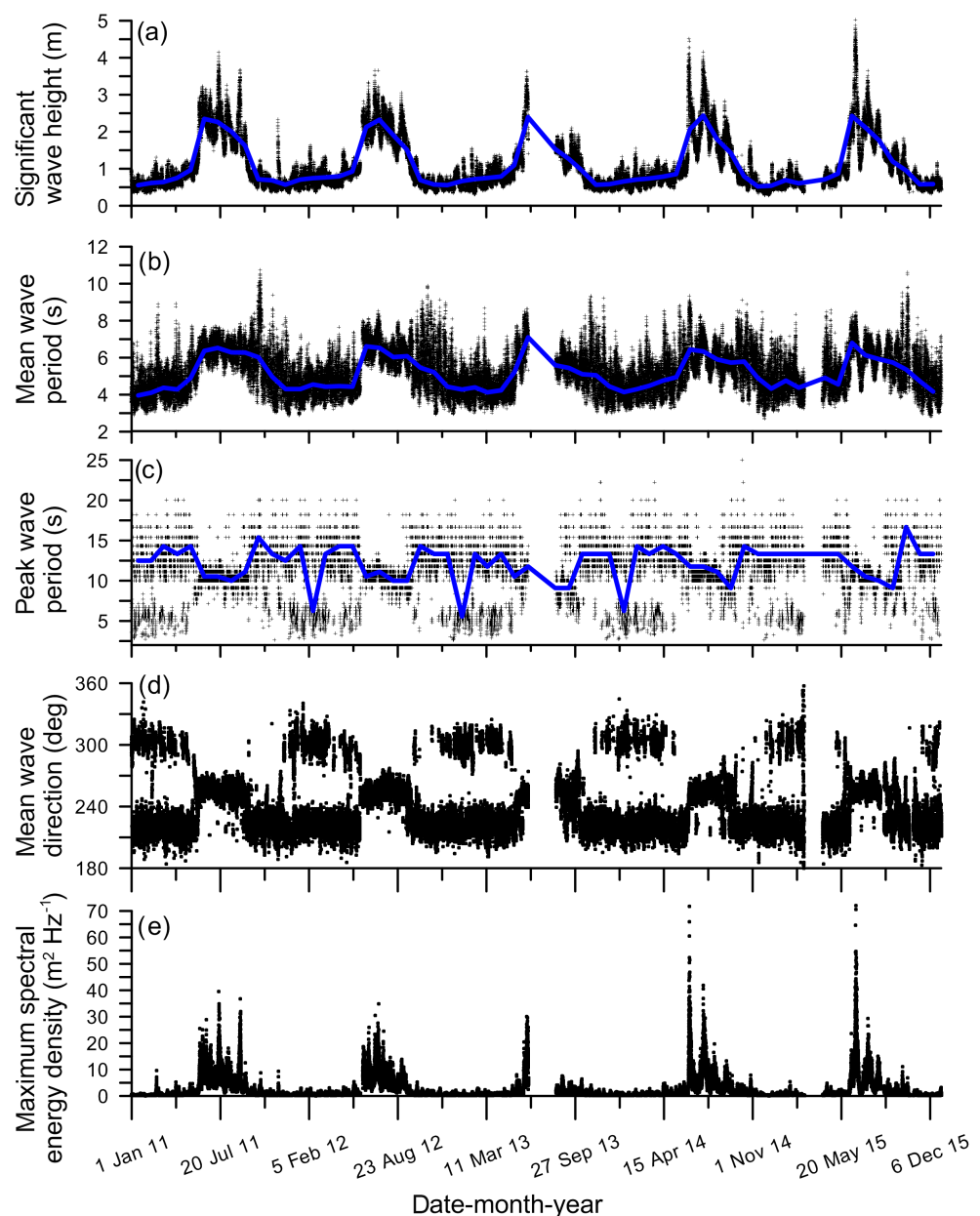

Figure 2. A time series plot of (a) the significant wave height, (b) mean wave period, (c) peak wave period, (d) mean wave direction and (e) maximum spectral energy density from 1 January 2011 to 31 December 2015. The thick blue line indicates the monthly average values.

\section{Results and discussions}

\subsection{Bulk wave parameters}

The wave conditions $(\sim 75 \%)$ at the buoy location are mostly intermediate- and shallow-water waves (where the water depth is less than half the wavelength, $d<L / 2$ ). This condition is not satisfied during $\sim 25 \%$ of the time due to waves with mean periods of $4.4 \mathrm{~s}$ or less. This study therefore deals with shallow, intermediate and deepwater wave climatology. Hence, bathymetry will significantly influence the wave characteristics.

The persistent monsoon winds generate choppy seas with average wave heights of $2 \mathrm{~m}$ and mean wave periods of $6.5 \mathrm{~s}$. Figure 2 shows that in the monsoon, the observed waves had a maximum $H_{\mathrm{m} 0}$ of about $5 \mathrm{~m}$, with $H_{\mathrm{m} 0}$ of $2-2.5 \mathrm{~m}$ more common during this period. The maximum $H_{\mathrm{m} 0}$ measured during the study period is on 21 June 2015 at 17:30 UTC (Fig. 2a). The mean wave periods $\left(T_{\mathrm{m} 02}\right)$ at the measurement location ranged from 4-8 s (Fig. 2b). The wave direction dur- ing the monsoon is predominantly from the west due to refraction towards the coast. The fluctuation in $H_{\mathrm{mo}}$ due to the southwest monsoon is seen in all the years (Fig. 2a). High waves $\left(H_{\mathrm{m} 0}>2 \mathrm{~m}\right)$ during 27-29 November 2011 are due to the deep depression ARB 04 formed in the AS. During the study period, the annual average $H_{\mathrm{m} 0}$ is the same $(\sim 1.1 \mathrm{~m})$ in all the years (Table 1). In 2013, the data for July could not be collected, hence resulting in a lower annual average $H_{\mathrm{m} 0}$. Over the 5 years, small waves $\left(H_{\mathrm{m} 0}<1 \mathrm{~m}\right)$ account for a large proportion (63.94\%) of the measured data and only during $0.16 \%$ of the time did $H_{\mathrm{m} 0}$ exceed $4 \mathrm{~m}$ (Table 2). The 25th and 75th percentiles of the $H_{\mathrm{m} 0}$ distribution over the entire analysis period are 0.6 and $1.4 \mathrm{~m}$.

The waves with low heights $\left(H_{\mathrm{m} 0}<1 \mathrm{~m}\right)$ have mean periods in a large range $(2.7-10.5 \mathrm{~s})$, whereas the high waves $\left(H_{\mathrm{m} 0}>3 \mathrm{~m}\right)$ have a mean wave period in a narrow range (6.1-9.3 s) (Table 2). For waves with $H_{\mathrm{m} 0}$ higher than $3 \mathrm{~m}$, the $T_{\mathrm{p}}$ never exceeded $14.3 \mathrm{~s}$, and for waves with $H_{\mathrm{m} 0}$ less than $1 \mathrm{~m}, T_{\mathrm{p}}$ up to $22.2 \mathrm{~s}$ are observed (Fig. 2c). The longperiod swells $(14-20 \mathrm{~s})$ have $H_{\mathrm{m} 0}<2.5 \mathrm{~m}$. Around $7 \%$ of 


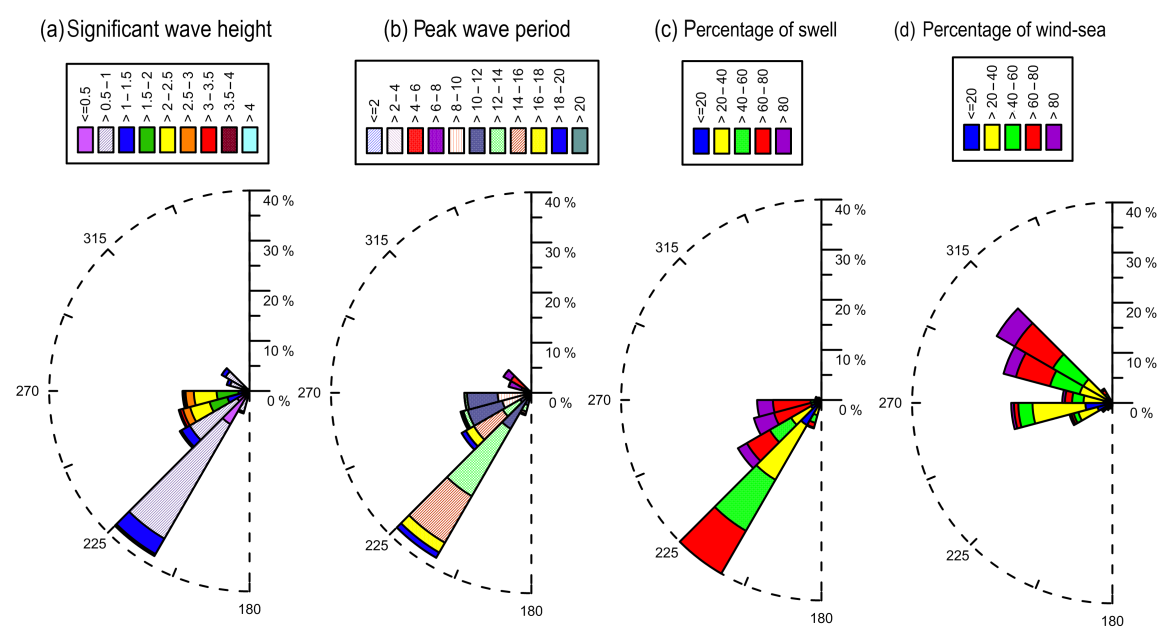

Figure 3. Wave roses during 2011-2015 for (a) the significant wave height and mean wave direction, (b) the peak wave period and mean wave direction, (c) the percentage of swell, (d) the percentage of wind-sea and mean wave direction.

Table 1. The amount of data used in the study in different years along with the range of significant wave heights and average values.

\begin{tabular}{lllll}
\hline \multirow{2}{*}{ Year } & \multicolumn{2}{c}{ Significant wave height $(\mathrm{m})$} & \multirow{2}{*}{$\begin{array}{c}\text { Amount } \\
\text { of data }\end{array}$} & $\begin{array}{c}\% \text { of } \\
\text { data }\end{array}$ \\
\cline { 2 - 4 } & Range & Average & 17517 & 99.98 \\
2011 & $0.3-4.4$ & 1.1 & 17323 & 98.61 \\
2012 & $0.3-3.7$ & 1.1 & 14531 & 82.94 \\
2013 & $0.3-3.6$ & $0.9^{*}$ & 17284 & 98.65 \\
2014 & $0.3-4.5$ & 1.1 & 14772 & 84.32 \\
2015 & $0.3-5.0$ & 1.1 & & \\
\hline
\end{tabular}

* The average value is estimated excluding the July data.

the time during 2011-2015, the waves had peak periods of more than $16.7 \mathrm{~s}$ (Table 3). Peak frequencies between 0.08 and $0.10 \mathrm{~Hz}$, equivalent to a peak wave period of 10 $12.5 \mathrm{~s}$, are observed $31.15 \%$ of the time, and the $H_{\mathrm{m} 0}$ is also relatively high $(\sim 1.55 \mathrm{~m})$ for waves in this class. During the annual cycle, the wave climate is dominated by low- $\left(0.5>H_{\mathrm{m} 0}>1 \mathrm{~m}\right)$ and intermediate-period $\left(T_{\mathrm{p}} \sim 10\right.$ $16 \mathrm{~s})$ southwesterly swells. Waves from the northwest have a $T_{\mathrm{p}}$ less than $8 \mathrm{~s}$ (Fig. 3).

The wave roses during 2011-2015 indicate that around $38 \%$ of the time, the predominant wave direction is SSW $\left(225^{\circ}\right)$ with long-period (14-18 s) and intermediate-period (10-14 s) waves (Fig. 3). A small percentage of long-period waves having $H_{\mathrm{m} 0}$ more than $1 \mathrm{~m}$ are observed from the same direction, for which more than $80 \%$ are swells (Fig. 3c). Intermediate-period waves observed with $H_{\mathrm{m} 0}$ less than $1 \mathrm{~m}$ contain $20-60 \%$ swells. Around $10-15 \%$ of the waves observed during the period are from the west, which includes intermediate- and short-period waves with $H_{\mathrm{m} 0}$ varying from 1.5 to $3 \mathrm{~m}$. These intermediate-period waves from the west with $H_{\mathrm{m} 0}$ between 2.5 and $3 \mathrm{~m}$ contain more than $80 \%$ swells. Waves from the NW are short-period waves with $H_{\mathrm{m} 0}$ between 0.5 and 1.5 ; the swell percentage is very low, showing the influence of the wind-sea (Fig. 3d). The high waves observed in the study area consist of more than $80 \%$ swells.

The date-versus-year plots of the significant wave height (Fig. 4) show that $H_{\mathrm{m} 0}$ has its maximum values $\left(H_{\mathrm{m} 0}>3 \mathrm{~m}\right)$ during the monsoon period with a wave direction of WSW and a peak wave period of 10-12s (the intermediate period). The mean wave period shows its maximum values (6-8 s) during the monsoon period. During January-May in all the years, $H_{\mathrm{m} 0}$ is low $\left(H_{\mathrm{m} 0}<1 \mathrm{~m}\right)$ with waves from the $\mathrm{SW}, \mathrm{W}$ and NW directions. The NW waves observed are the result of strong sea breezes during this period. Longperiod $\left(T_{\mathrm{p}}>14 \mathrm{~s}\right)$, intermediate-period $\left(10<T_{\mathrm{p}}<14 \mathrm{~s}\right)$ and short-period $\left(T_{\mathrm{p}}<8 \mathrm{~s}\right)$ waves are observed during this period; hence, the mean wave period observed is low compared to the monsoon (Fig. 4d). From October to December, similar to the pre-monsoon period, the $H_{\mathrm{m} 0}$ observed is less than $1 \mathrm{~m}$, but the wave direction is predominantly from the SW and W with the least NW waves. Short-period waves are almost absent during this period, and the condition is similar for all the years. The interannual variations in $H_{\mathrm{m} 0}$ are less than $15 \%$ (Fig. 4). The primary seasonal variability in the waves is due to the monsoonal wind reversal. During January-March, there is a shift in the occurrences of northwest swells.

\subsection{Wave spectrum}

The normalized wave spectral energy density contours are presented for different years to identify the wind-sea or swell predominance (Fig. 5). The normalization of the wave spectrum is done to determine the spread of energy in different frequencies. Since the range of the maximum spectral energy density in a year is large $\left(\sim 60 \mathrm{~m}^{2} \mathrm{~Hz}^{-1}\right)$, each wave spectrum is normalized by dividing the spectral energy density 
Table 2. The characteristics of waves in different ranges of significant wave height.

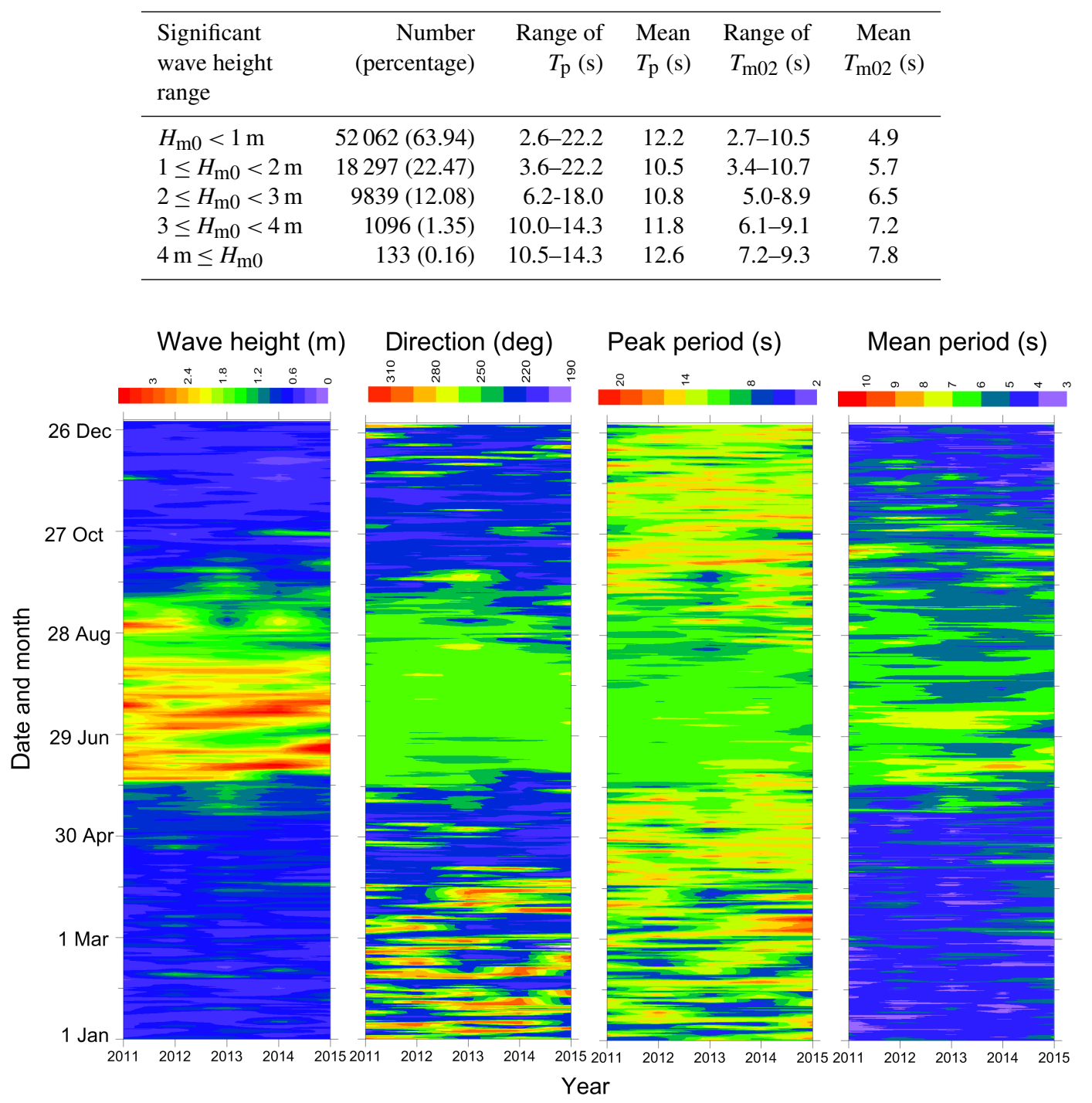

Figure 4. A date-versus-year plot of (a) the significant wave height, (b) mean wave direction, (c) peak wave period and (d) mean wave period.

by the maximum spectral energy density of that spectrum. The predominance of both the wind-seas and swells is observed in the non-monsoon period, whereas in the monsoon period only swells are predominant (Fig. 5). The separation of swells and wind-seas indicates that over an annual cycle, around $54 \%$ of the waves are swells. Glejin et al. (2012) reported that the dominance of swells during the monsoon is due to the fact that even though the wind in the study region is strong during the monsoon, the wind over the entire AS will also be strong. When these swells are added to the wave system at the buoy location, the energy of the swell increases (Donelan, 1987) and will result in the dominance of swells. The spread of spectral energy to higher frequencies $(0.15$ to $0.25 \mathrm{~Hz}$ ) is predominant during January-May (Fig. 5) due to the sea breeze in the pre-monsoon period (Neetu et al., 2006; Dora and Sanil Kumar, 2015). In the monsoon during the wave growth period, the spectral peak shifts from 0.12 0.13 to $0.07-0.09 \mathrm{~Hz}$ (lower frequencies).

An interesting phenomenon is that the long-period ( $>18 \mathrm{~s}$ ) swells are present for $2.5 \%$ of the time during the study period. The buoy location at $15 \mathrm{~m}$ of water depth is exposed to waves from the northwest to the south with the nearest landmass at $\sim 1500 \mathrm{~km}$ to the northwest (Asia), $\sim 2500 \mathrm{~km}$ to the west (Africa), $\sim 4000 \mathrm{~km}$ to the southwest (Africa) and $\sim 9000 \mathrm{~km}$ to the south (Antarctica) (Amrutha et al., 2017). Due to its exposure to the southern oceans and the large fetch available, swells are present all year round in the study area, and the swells are dominant in the non-monsoon pe- 

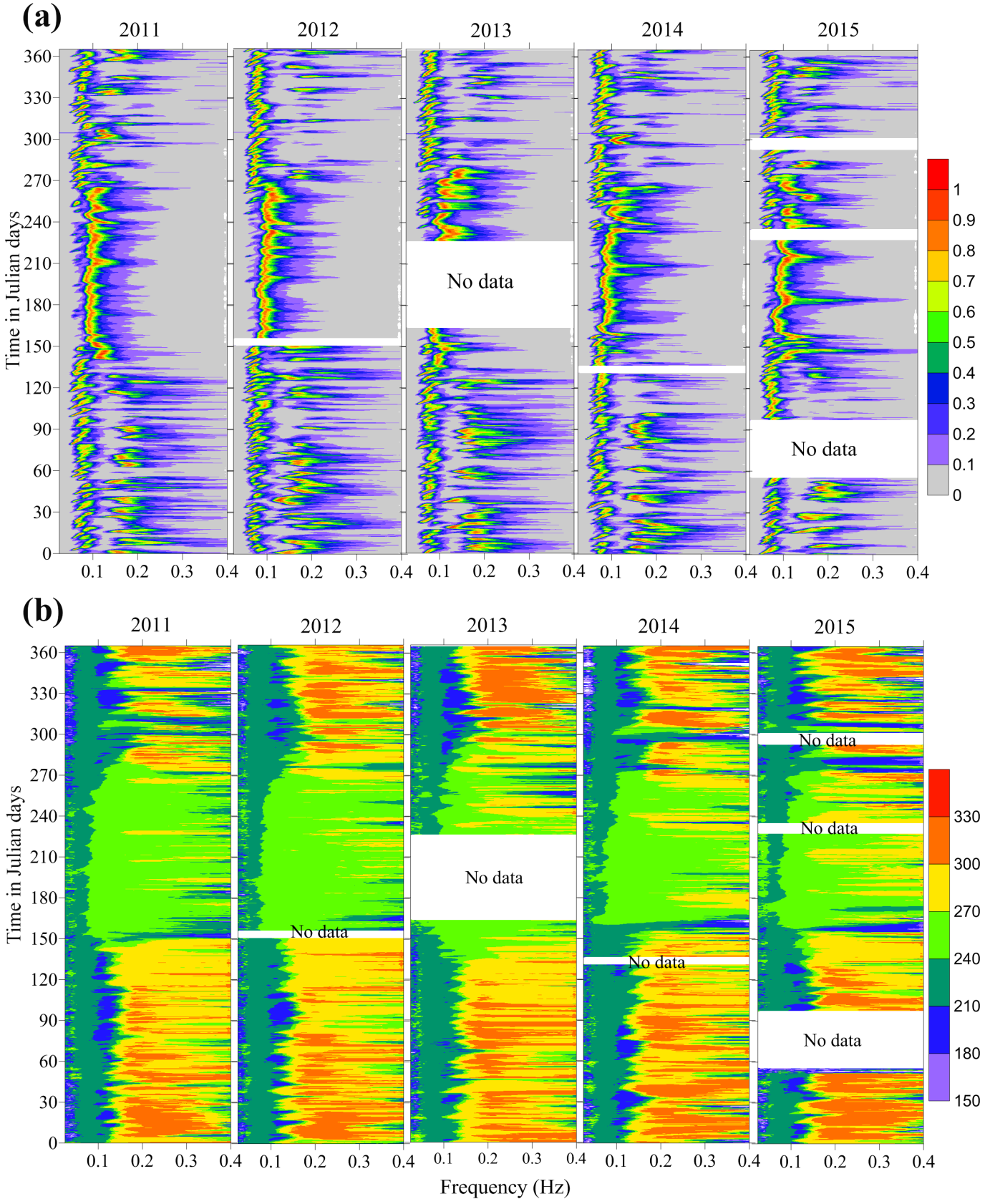

Figure 5. The temporal variation in the normalized spectral energy density (a) and the mean wave direction (b) with frequency in different years. The value used for normalizing the spectral energy density is presented in Fig. 2e.

riod (Glejin et al., 2013). Throughout the year, waves with periods of more than $10 \mathrm{~s}$ (low-frequency $<0.1 \mathrm{~Hz}$ waves) are the southwest swells, whereas the direction of shortperiod waves changes with the seasons (Fig. 5). Amrutha et al. (2017) reported that the long-period waves observed in the eastern AS are the swells generated in the southern Indian Ocean. In the monsoon season, the waves with high frequencies are predominantly from the west-southwest, whereas in the non-monsoon period they are from the northwest. In the non-monsoon period, the predominance of wind- seas and swells fluctuated, and hence the mean wave direction also changed frequently (Fig. 5). The average direction of waves with $H_{\mathrm{m} 0}<1 \mathrm{~m}$ shows the northwest windseas and the southwest swells, whereas for the high waves $\left(H_{\mathrm{m} 0}>3 \mathrm{~m}\right)$, the difference between the swell and wind-sea direction decreases. This is because the high waves become aligned with the bottom contour before $15 \mathrm{~m}$ of water depth on their approach to the shallow water.

The interannual changes in the wave spectral energy density for different months in the period 2011-2015 are stud- 
Table 3. The average wave parameters and the amount of data in different spectral peak frequencies.

\begin{tabular}{lrccr}
\hline $\begin{array}{l}\text { Frequency }\left(f_{\mathrm{p}}\right) \\
\text { range }(\mathrm{Hz})\end{array}$ & $\begin{array}{r}\text { Amount of } \\
\text { data and \% }\end{array}$ & $\begin{array}{c}H_{\mathrm{m} 0} \\
(\mathrm{~m})\end{array}$ & $\begin{array}{c}T_{\mathrm{m} 02} \\
(\mathrm{~s})\end{array}$ & $\begin{array}{r}\text { Peak wave } \\
\text { period }(\mathrm{s})\end{array}$ \\
\hline $0.04<f_{\mathrm{p}} \leq 0.05$ & $318(0.39)$ & 0.73 & 5.24 & 20.19 \\
$0.05<f_{\mathrm{p}} \leq 0.06$ & $5341(6.56)$ & 0.82 & 5.48 & 17.16 \\
$0.06<f_{\mathrm{p}} \leq 0.07$ & $14764(18.13)$ & 0.75 & 5.22 & 14.73 \\
$0.07<f_{\mathrm{p}} \leq 0.08$ & $18221(22.38)$ & 0.80 & 5.05 & 12.96 \\
$0.08<f_{\mathrm{p}} \leq 0.10$ & $25364(31.15)$ & 1.55 & 5.76 & 10.88 \\
$0.10<f_{\mathrm{p}} \leq 0.15$ & $9459(11.62)$ & 1.25 & 5.35 & 8.07 \\
$0.15<f_{\mathrm{p}} \leq 0.20$ & $6355(7.80)$ & 0.76 & 4.43 & 5.72 \\
$0.20<f_{\mathrm{p}} \leq 0.30$ & $1487(1.83)$ & 0.78 & 3.86 & 4.36 \\
$0.30<f_{\mathrm{p}} \leq 0.50$ & $118(0.14)$ & 0.66 & 3.22 & 3.09 \\
\hline
\end{tabular}

ied by computing the monthly average wave spectra for all the years (Fig. 6). In the non-monsoon period, the wave spectra observed are double peaked, indicating the presence of wind-seas and swells. During the monsoon, due to the strong southwest winds, a single-peaked spectrum is observed, i.e., a swell peak with a low frequency and a high spectral energy density. Along the Indian coast, Harish and Baba (1986), Rao and Baba (1996) and Sanil Kumar et al. (2003) found that wave spectra are generally multi-peaked and that the double-peaked wave spectra are more frequent during low-sea states (Sanilkumar et al., 2004). Sanil Kumar et al. (2014), Sanil Kumar and Anjali (2015) and Anjali and Sanil Kumar (2016) have also observed that doublepeaked spectra in the monsoon period in the eastern AS are due to the locally generated wind-seas and the southern Indian Ocean swells. In the study area from January to May and October to December, the swell peak is between the frequencies 0.07 and $0.08 \mathrm{~Hz}\left(12.5<T_{\mathrm{p}}<14.3 \mathrm{~s}\right)$; but in the monsoon period, the swell peak is around $0.10 \mathrm{~Hz}$ in all the years studied. This shows the presence of longperiod swells $\left(T_{\mathrm{p}}>13 \mathrm{~s}\right)$ in the non-monsoon period and intermediate-period swells $\left(8<T_{\mathrm{p}}<13 \mathrm{~s}\right)$ in the monsoon. Glejin et al. (2016) also observed the presence of lowamplitude long-period waves in the eastern AS in the nonmonsoon period and intermediate-period waves in the monsoon period. This is because the propagation of swells from the Southern Hemisphere is more visible during the nonmonsoon period due to the calm conditions (low wind-seas) prevailing in the eastern AS. During the monsoon period, these swells occur less often due to the turbulence in the northern Indian Ocean (Glejin et al., 2013).

Large interannual variations are observed for the monthly average wave spectrum in all months except July. This is because July is known to be the roughest month over the entire annual cycle, and the southwest monsoon reaches its peak during July. Hence, the influence of temporally varying wind-seas on the wave spectrum is the lowest during July compared to other months. Due to the early onset (on 1 June) and advancement of the monsoon during 2013 compared to
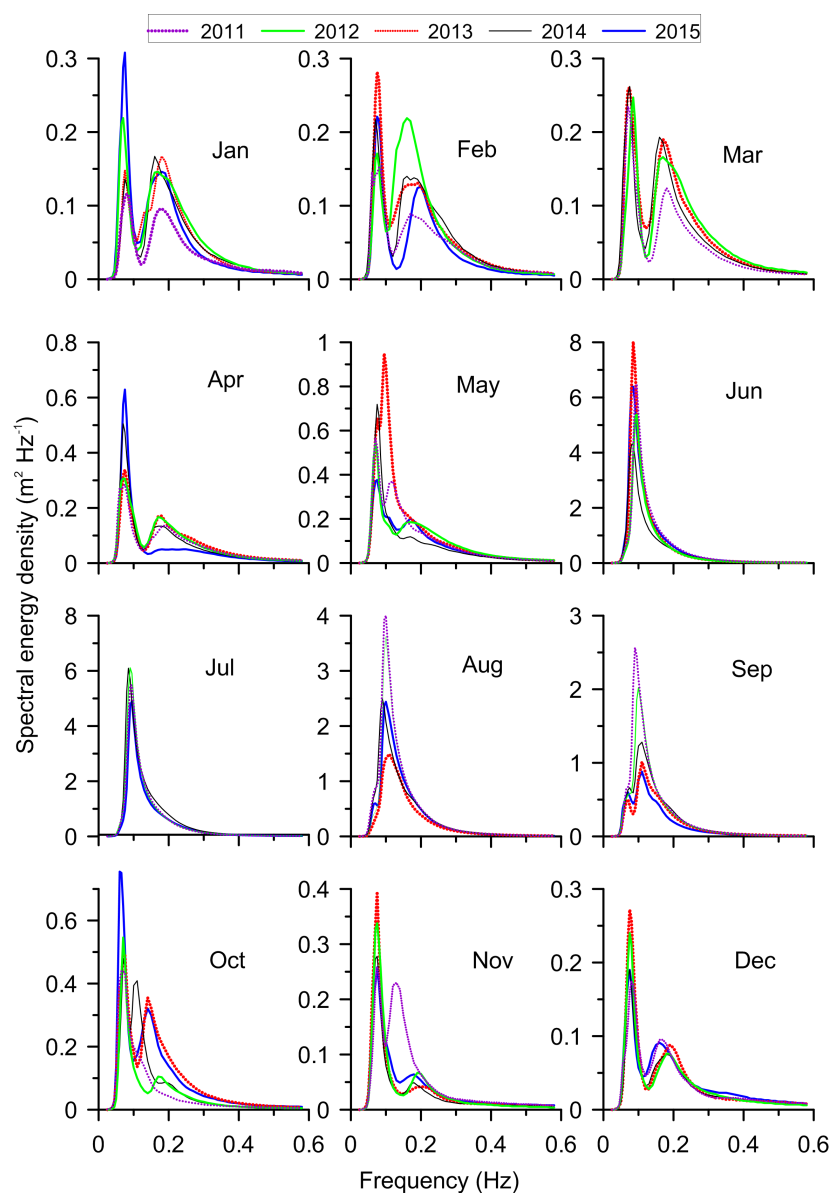

Figure 6. The monthly average wave spectra from 2011 to 2015.

other years, the monthly average value of the maximum spectral energy is observed in June 2013 (Fig. 6). The wave spectra of November 2011 are distinct from those of other years, with a low wind-sea peak frequency of $0.13 \mathrm{~Hz}$ due to the deep depression ARB 04 that occurred south of India near Cape Comorin from 26 November to 1 December with a sustained wind speed of $55 \mathrm{~km} \mathrm{~h}^{-1}$. During October 2014, the second peak is observed at $0.11 \mathrm{~Hz}$ with comparatively high energy, showing the influence of the cyclonic storm Nilofar. It is an extremely severe cyclonic storm that occurred during the period 25-31 October 2014, originating from a low-pressure area between the Indian and Arabian peninsulas. The highest wind speed was $215 \mathrm{~km} \mathrm{~h}^{-1}$, and the affected areas included India, Pakistan and Oman. Significant interannual variation is observed in the wind-sea peak frequency. The wave spectra averaged over each season (Fig. 7) show that the interannual variations in the energy spectra averaged over the full-year period almost follow the pattern of the wave spectra averaged over the monsoon period. This indicates the strong influence of monsoon winds on the wave energy spectra in the study area. Interannual variations within the spectrum are higher for the wind-sea region compared 


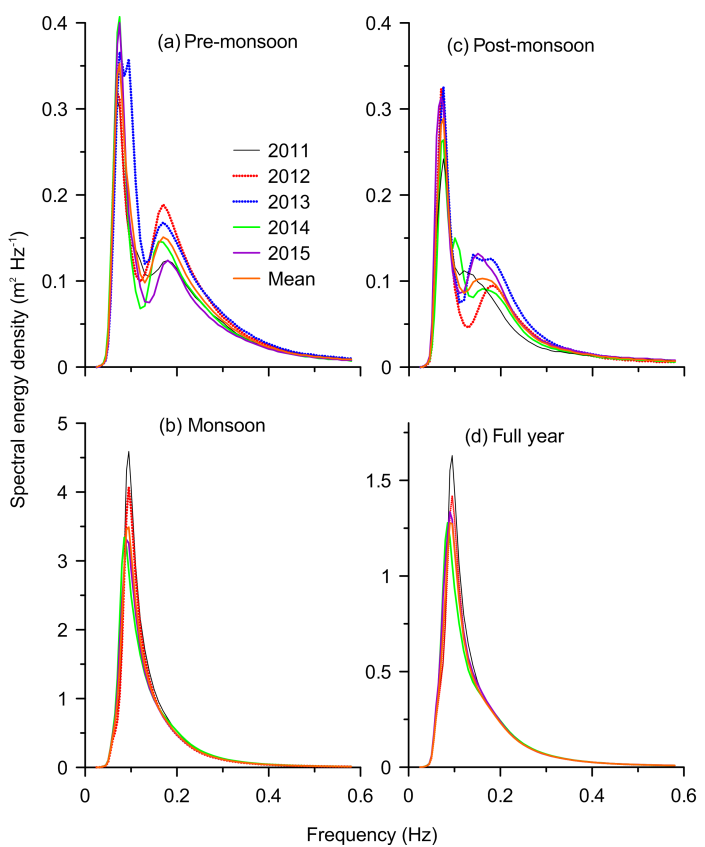

Figure 7. The wave spectra averaged over (a) the pre-monsoon period (February-May), (b) the monsoon period (June-September), (c) the post-monsoon period (October-January) and (d) the full year in different years.

to the swell region. During the study period, the maximum spectral energy observed is during the 2011 monsoon.

For different frequencies, the monthly average wave direction is shown in Fig. 8. It is observed that throughout the year, the mean wave direction of the swell peak is southwest $\left(200-250^{\circ}\right)$. In the non-monsoon period, the wind-sea direction is northwest $\left(280-300^{\circ}\right)$, except in October and November. This is due to the wind-seas produced by the sea breeze, which has the maximum intensity during the premonsoon season. Interannual variability in the wave direction is the highest during October and November, when the wind-seas from the southwest direction are also observed. This is because during these months, the wind speed and the strength of the monsoon swell decreases, which makes the low-energy wind-seas produced by the withdrawing monsoon winds more visible.

Contour plots of the spectral energy density (normalized) clearly show the predominance of wind-seas and swells during the non-monsoon period (Fig. 9). Only Figs. 5 and 9 present the normalized spectral energy density. In the monsoon period, the spectral energy density is mainly confined to a narrow frequency range $(0.07-0.14 \mathrm{~Hz})$ and the wave spectra are mainly single peaked with a maximum energy within the frequency range of $0.08-0.10 \mathrm{~Hz}$ and a direction of $240^{\circ}$. Glejin et al. (2012) reported that in the monsoon season, the spectral peak is between 0.08 and $0.10 \mathrm{~Hz}(12-$ 10 s) for $\sim 72 \%$ of the time in the eastern AS. Earlier studies also reported the dominance of swells in the eastern AS

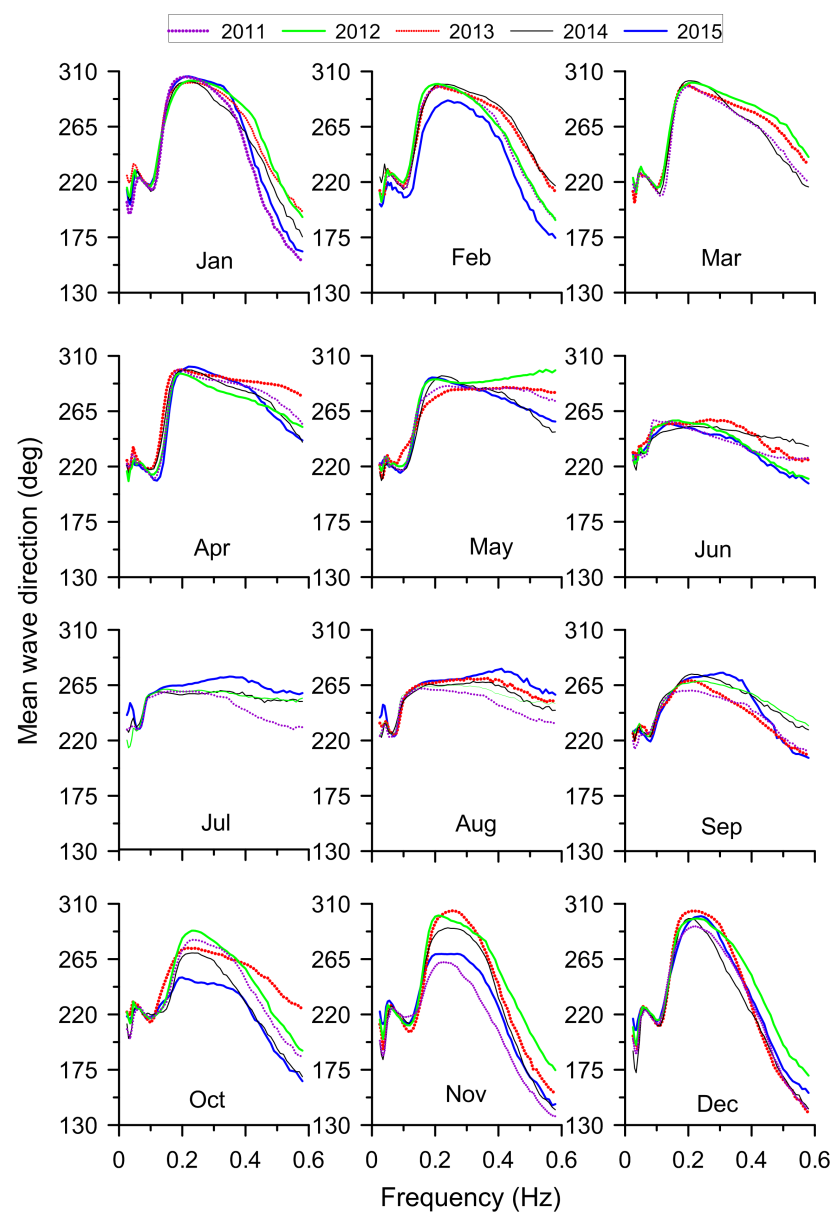

Figure 8. The monthly average wave direction at different frequencies in different months.

during the monsoon (Sanil Kumar et al., 2012; Glejin et al., 2012). Above $0.15 \mathrm{~Hz}$, energy gradually decreases with the lowest energy observed between 0.30 and $0.50 \mathrm{~Hz}$. Wind-sea energy is comparatively low during October, November and December and occurs mostly in the frequency range lower than $0.20 \mathrm{~Hz}$; during January-May, the frequency exceeds $0.20 \mathrm{~Hz}$. In the pre-monsoon period, the wind-sea plays a major role in the nearshore wave environment (Rao and Baba, 1996). Wind-sea energy is found to be low during April 2015 (Fig. 6) because of a reduction in local winds. The occurrence of wind-seas is very low during November in most years, except during 2011 due to the deep depression ARB 04.

The behavior of the high-frequency part of the spectrum is governed by the energy balance of the waves generated by the local wind fields. When the wind blows over a long fetch or for a long time, the wave energy for a given frequency reaches the equilibrium range and the energy input from the wind is balanced by energy loss to lower frequencies and by wave breaking (Torsethaugen and Haver, 2004). The highfrequency tail slope of the monthly average wave spectrum in different years shows that the slope is high $(b<-3.1)$ during 


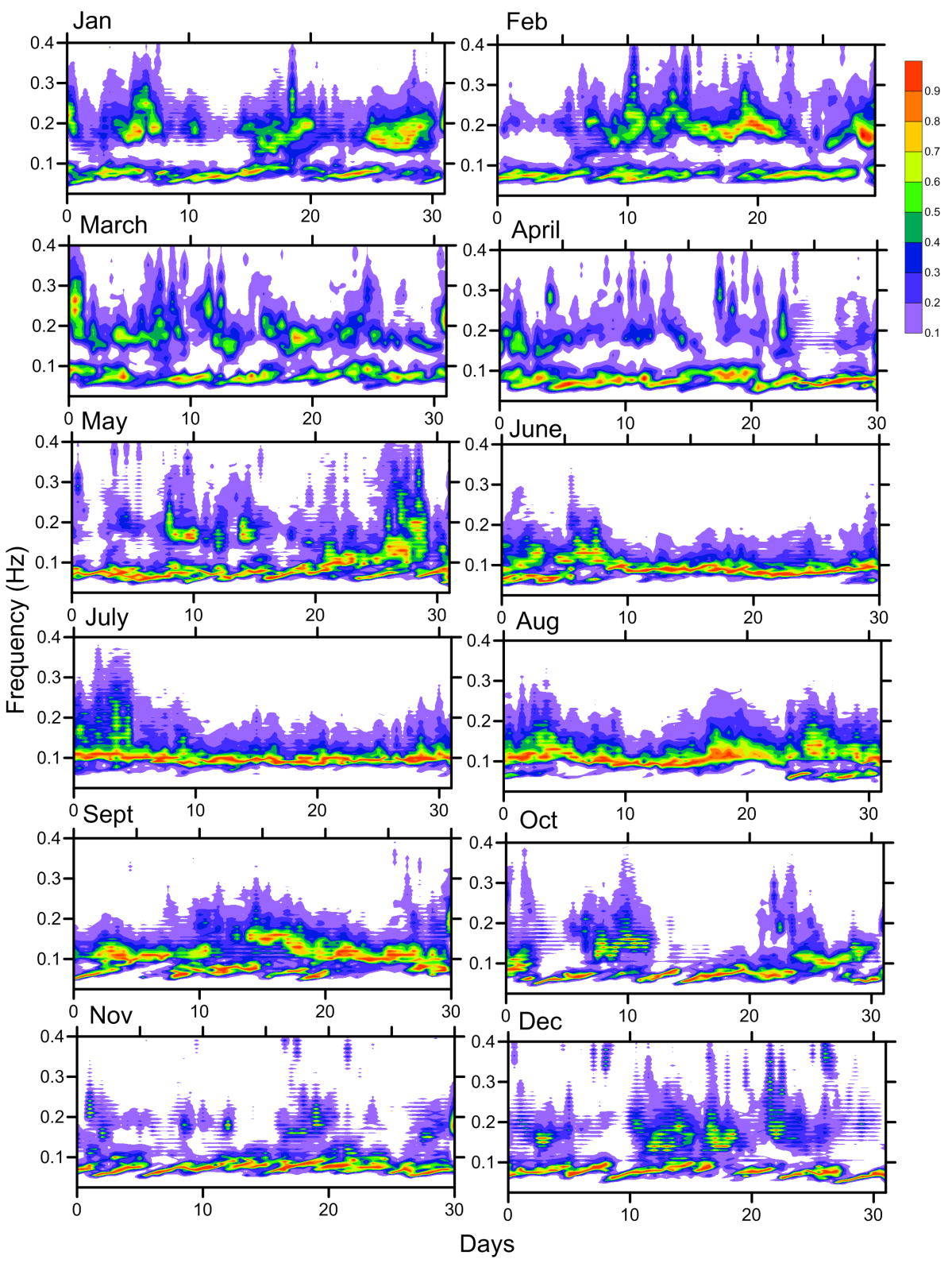

Figure 9. The temporal variation in the normalized spectral energy density in different months (data from 2011 to 2015 ). The value used for normalizing the spectral energy density is presented in Fig. 2e.

June to September; the case is same for all the years studied (Table 4). During all other months, the exponent in the expression for the frequency tail is within the range of -3.1 to -1.5 . The distribution of the exponent values for different significant wave height ranges shows that the slope increases (exponent decrease from -2.44 to -4.20 ) as the significant wave height increases and reaches a saturation range (Table 5). For frequencies from 0.23 to $0.58 \mathrm{~Hz}$ in the eastern AS during January-May, Amrutha et al. (2017) observed that the high-frequency tail has the $f^{-2.5}$ pattern at $15 \mathrm{~m}$ of water depth. For frequencies ranging from 0.31 to $0.55 \mathrm{~Hz}$, the high-frequency tail follows $f^{-3}$ at $5 \mathrm{~m}$ of water depth. Since
$H_{\mathrm{m} 0}$ is maximum during the monsoon period, the slope is also maximum from June to September. There is not much interannual variation in the slope for swell-dominated spectra during the monsoon, while in the non-monsoon period when the wind-seas have a high level of influence, the slope varies significantly.

The most obvious manifestations of nonlinearity are the sharpening of the wave crests and the flattening of the wave troughs, and these effects are reflected in the skewness of the sea surface elevation (Toffoli et al., 2006). Zero skewness indicates linear sea states, and a positive skewness value indicates that the wave crests are bigger than the troughs. Fig- 
Table 4. The exponent of the high-frequency tail of the monthly average wave spectra in different years.

\begin{tabular}{lcccccc}
\hline \multirow{2}{*}{ Months } & \multicolumn{6}{c}{ Exponent of the high-frequency tail } \\
\cline { 2 - 7 } & 2011 & 2012 & 2013 & 2014 & 2015 & $2011-$ \\
& & & & & & 2015 \\
\hline January & -2.08 & -2.93 & -2.97 & -2.72 & -2.81 & -2.72 \\
February & -2.41 & -3.02 & -2.74 & -2.99 & -3.06 & -2.85 \\
March & -2.75 & -2.91 & -2.82 & -2.76 & No data & -2.81 \\
April & -2.56 & -2.74 & -2.64 & -2.71 & -2.19 & -2.60 \\
May & -2.59 & -2.67 & -2.63 & -2.42 & -2.51 & -2.56 \\
June & -3.64 & -3.53 & -3.55 & -3.82 & -3.58 & -3.55 \\
July & -3.76 & -3.55 & No data & -3.82 & -3.63 & -3.70 \\
August & -3.63 & -3.58 & -3.40 & -3.52 & -3.65 & -3.58 \\
September & -3.41 & -3.44 & -3.16 & -3.38 & -3.00 & -3.30 \\
October & -2.02 & -2.77 & -3.03 & -2.52 & -2.61 & -2.68 \\
November & -1.78 & -2.43 & -1.77 & -1.55 & -1.65 & -1.84 \\
December & -1.69 & -2.23 & -1.95 & -2.06 & -1.79 & -1.94 \\
\hline
\end{tabular}

Table 5. The exponent of the high-frequency tail of the average wave spectra in different wave height ranges.

\begin{tabular}{lc}
\hline $\begin{array}{l}\text { Range of } \\
H_{\mathrm{m} 0}(\mathrm{~m})\end{array}$ & $\begin{array}{c}\text { Exponent of the } \\
\text { high-frequency tail }\end{array}$ \\
\hline $0-1$ & -2.44 \\
$1-2$ & -3.26 \\
$2-3$ & -3.67 \\
$3-4$ & -4.21 \\
$4-5$ & -4.21 \\
\hline
\end{tabular}

ure 10 shows that nonlinearity increases with an increase in $H_{\mathrm{m} 0}$. The slope of the high-frequency end of the wave spectrum becomes steeper when the wave nonlinearity increases. Donelan et al. (2012) found that in addition to the $\mathrm{k}^{-4}$ dissipation, swells modulate the equilibrium in breaking waves dependent on the mean surface slope, while Melville (1994) also quantified a relation between wave packet slopes and the dissipation rate. These results are specific to breaking waves, but one might expect similar relations between surface dynamics and dissipation rates for non-breaking waves. A function of the form $A \cdot \exp \left(\lambda H_{\mathrm{m} 0}\right)+s 0$ with the initial parameters of $A=8, \lambda=-2.4, s 0=-3.7$ is found to fit the exponent of the high-frequency tail data with the significant wave height (Fig. 11a). The functional representation of the exponent of the high-frequency tail data with $H_{\mathrm{m} 0}$ is shown in Fig. 11a and might be useful in revealing the physical connection; at the very least, it could provide a predictive basis for relating spectral slopes with mean significant wave heights as a basis for future research. It is shown in Fig. $11 \mathrm{~b}$ that the exponent decreases (slope increases) as the mean wave period increases. The study shows that the tail of the spectrum is influenced by the local wind conditions (Fig. 11c), and the influence is higher on the zonal component $(u)$ of the wind than on the meridional component $(v)$ (Fig. 11e and f). The exponent of the high-frequency tail de-
Table 6. The parameters of the fitted wave spectrum in different years.

\begin{tabular}{|c|c|c|c|c|c|}
\hline & \multirow[t]{2}{*}{ Year } & \multicolumn{2}{|c|}{ JONSWAP spectrum } & \multicolumn{2}{|c|}{ Donelan spectrum } \\
\hline & & $\alpha$ & $\Upsilon$ & $\alpha$ & $\Upsilon$ \\
\hline \multirow[t]{4}{*}{2011} & June & 0.0013 & 2.2 & 0.0028 & 2.0 \\
\hline & July & 0.0016 & 1.5 & 0.0021 & 1.7 \\
\hline & August & 0.0013 & 1.8 & 0.0029 & 1.7 \\
\hline & September & 0.0004 & 2.3 & 0.0021 & 1.6 \\
\hline \multirow[t]{4}{*}{2012} & June & 0.0015 & 1.6 & 0.0029 & 2.0 \\
\hline & July & 0.0010 & 2.1 & 0.0031 & 1.9 \\
\hline & August & 0.0009 & 2.2 & 0.0032 & 1.7 \\
\hline & September & 0.0006 & 2.0 & 0.0024 & 1.8 \\
\hline \multirow[t]{4}{*}{2013} & June & 0.0006 & 3.3 & 0.0030 & 1.9 \\
\hline & July & \multicolumn{4}{|c|}{ No data } \\
\hline & August & 0.0012 & 1.1 & 0.0038 & 1.4 \\
\hline & September & 0.0005 & 1.9 & 0.0042 & 1.4 \\
\hline \multirow[t]{4}{*}{2014} & June & 0.0010 & 1.1 & 0.0010 & 1.6 \\
\hline & July & 0.0006 & 2.5 & 0.0019 & 1.2 \\
\hline & August & 0.0006 & 1.5 & 0.0021 & 1.2 \\
\hline & September & 0.0011 & 1.1 & 0.0032 & 1.4 \\
\hline \multirow[t]{4}{*}{2015} & June & 0.0011 & 1.4 & 0.0023 & 1.8 \\
\hline & July & 0.0011 & 1.9 & 0.0024 & 1.8 \\
\hline & August & 0.0008 & 1.8 & 0.0024 & 1.4 \\
\hline & September & 0.0006 & 1.3 & 0.0043 & 1.6 \\
\hline
\end{tabular}

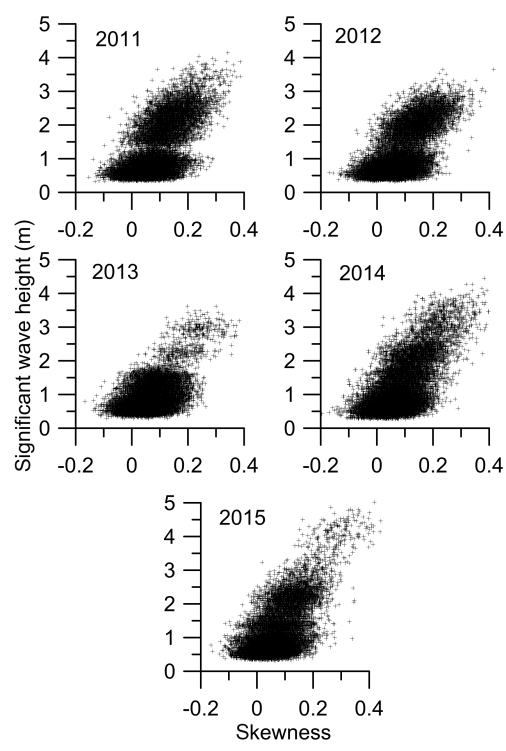

Figure 10. A scatter plot of the significant wave height with the skewness of the sea surface elevation in different years.

creases with the increase in the inverse wave age $\left(U_{10} / c\right)$, where $c$ is the celerity of the wave. 

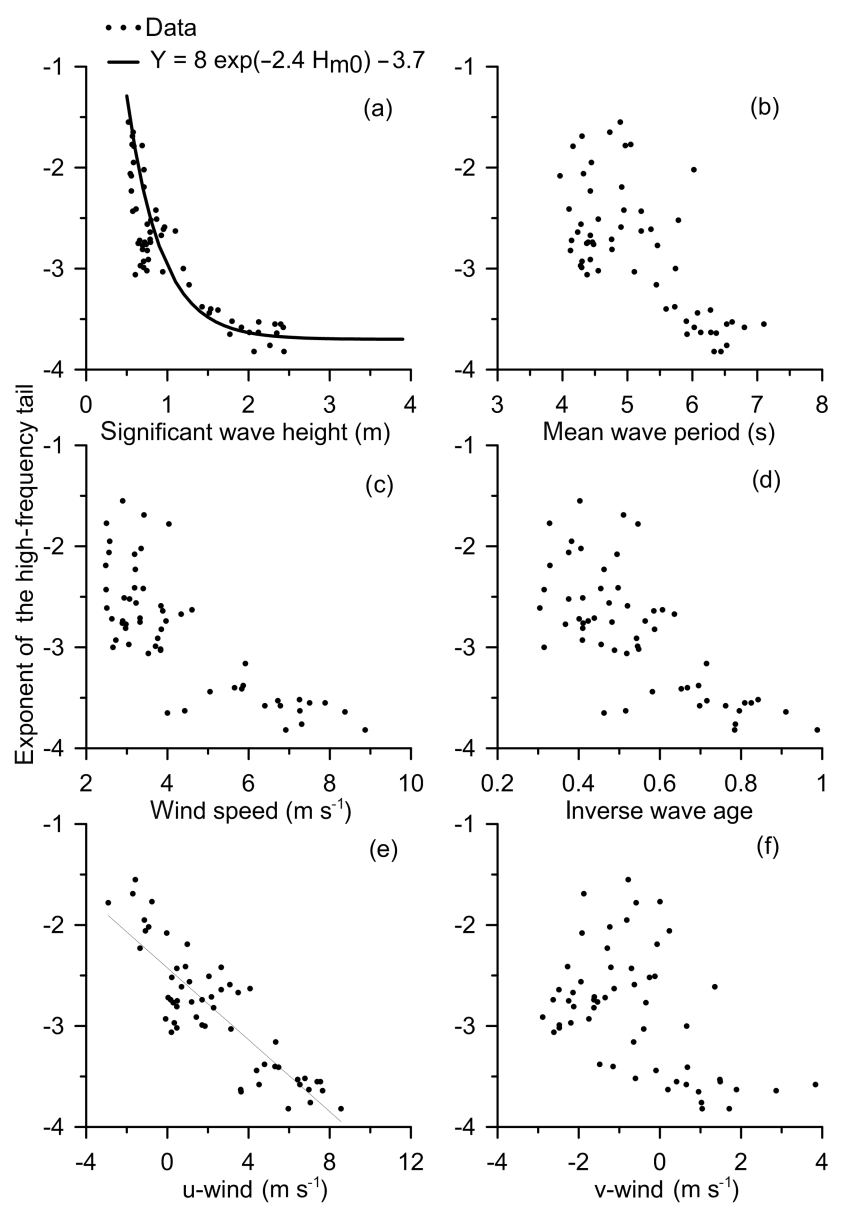

Figure 11. A plot of the exponent of the high-frequency tail with (a) the significant wave height, (b) mean wave period, (c) wind speed, (d) inverse wave age, (e) $u$-wind and (f) $v$-wind.

\subsection{Comparison with theoretical wave spectra}

In the monsoon period, the spectrum is single peaked with a high spectral energy density. During this period, the JONSWAP spectrum is fitted up to the peak frequency; after that, the Donelan spectrum is used. The monthly average wave spectra during the monsoon period for the year 2011 is compared with the JONSWAP and Donelan theoretical wave spectra in Fig. 12. It is found that the JONSWAP and Donelan spectra with modified parameters describe the wave spectra well at low frequencies and high frequencies, respectively. The values for $\alpha$ and $\Upsilon$ were varied from 0.0001 to 0.005 and 1.1 to 3.3 , respectively, to find the values for which the theoretical spectrum best fits the measured spectrum; those values were used to plot the theoretical spectrum. The values of $\alpha$ and $\Upsilon$ thus obtained for June, July, August and September are given in Table 6. From the table, the average values of $\alpha$ and $\Upsilon$ for the monsoon months are obtained as 0.0009 and 1.82 for the JONSWAP spectra and 0.0274 and 1.64 for the Donelan spectra. These values are lower than the

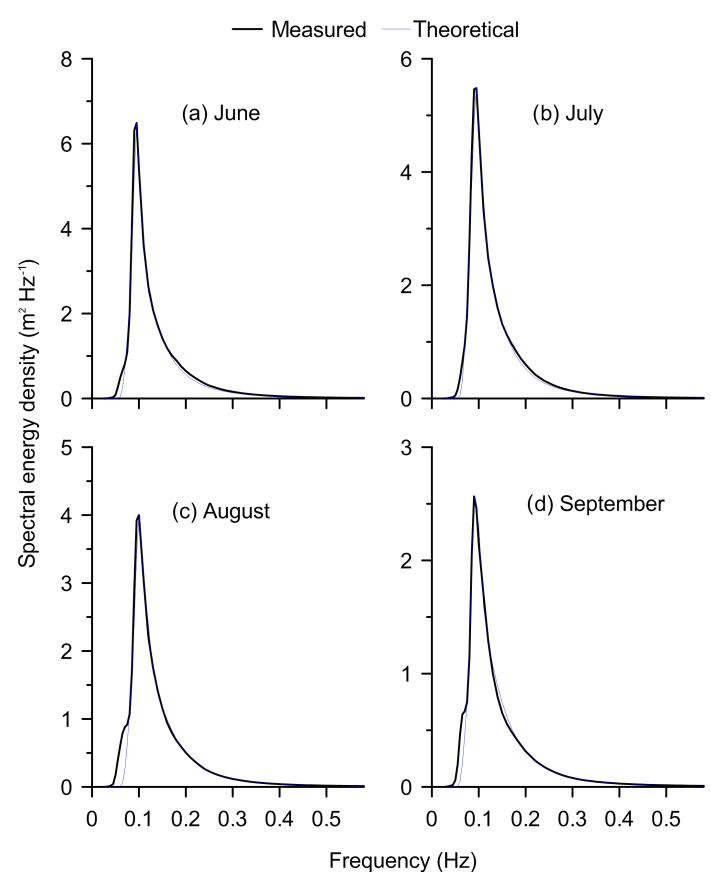

Figure 12. The fitted theoretical spectra along with the monthly average wave spectra for different months.

generally recommended values of $\alpha$ and $\Upsilon$, which are 0.0081 and 3.3. The $\alpha$ value is a constant that is related to the wind speed and fetch length. For all the data, the fitted Donelan spectrum is proportional to $f^{-n}$, where $\mathrm{n}$ is the exponent value of the high-frequency tail. The theoretical spectrum of JONSWAP and Donelan cannot completely describe the high-frequency tail of the measured spectrum since the highfrequency tail in these spectra decays in the forms of $f^{-5}$ and $f^{-4}$, respectively. Since the exponent of the high-frequency tail of the wave spectrum is within the range of -4 to -3 during the monsoon period, the Donelan spectrum shows a better fit for the monsoon spectra compared to other months (Fig. 11).

\section{Concluding remarks}

In this paper, the variations in the wave spectral shapes in different months for a nearshore location are investigated based on in situ wave data obtained from a moored directional waverider buoy. There are more interannual variations within the spectrum for wind-seas compared to swells. The maximum significant wave height measured at $15 \mathrm{~m}$ of water depth is $5 \mathrm{~m}$, and the annual average $H_{\mathrm{m} 0}$ has a similar value $(\sim 1.1 \mathrm{~m})$ in all the years. Over the 5 years, small waves $\left(H_{\mathrm{m} 0}<1 \mathrm{~m}\right)$ account for a large proportion of the measured data $(63.94 \%$ of the time). The study shows that high waves $\left(H_{\mathrm{m} 0}>2 \mathrm{~m}\right)$ have a spectral peak period between 8 and $14 \mathrm{~s}$, and the long-period swells $(14-20 \mathrm{~s})$ are $H_{\mathrm{m} 0}<2.5 \mathrm{~m}$. The high-frequency slope of the wave spectrum (the exponent de- 
creases from -2.44 to -4.20 ) increases with an increase in the significant wave height and the mean wave period. During the monsoon period, the Donelan spectrum shows a better fit for the monsoon spectra compared to other months, since the exponent of the high-frequency part of the wave spectrum is within the range of -4 to -3 . The decay of the high-frequency waves is the fastest with depth; hence, the high-frequency tail values observed in the study will be different for different water depths.

Data availability. The measured wave data used in the study can be requested from the corresponding author for joint research work. The wind speed at $10 \mathrm{~m}$ height is obtained from reanalysis data of zonal and meridional components (https://www.esrl.noaa.gov/psd/ data/gridded/data.ncep.reanalysis.html) at 6-hourly intervals from NCEP/NCAR (Kalnay et al., 1996).

Competing interests. The authors declare that they have no conflict of interest.

Acknowledgements. The authors acknowledge the Earth System Science Organization, Ministry of Earth Sciences, New Delhi for providing the financial support to conduct part of this research. We thank the following people for their help in the collection of data: T. M. Balakrishnan Nair, Head of OSISG; Arun Nherakkol, scientist at INCOIS, Hyderabad; and Jai Singh, technical assistant, CSIR-NIO. We thank U. G. Bhat and J. L. Rathod, Department of Marine Biology, Karnataka University PG Centre in Karwar for providing the logistics required for wave data collection. This work contributes to the $\mathrm{PhD}$ work of the first author (Anjali Nair). This paper is dedicated to the memory of our esteemed colleague, Ashok Kumar, in recognition of his substantial contributions in initiating the long-term wave measurements in the shallow waters around India. We thank the topic editor and both the reviewers for their critical comments and suggestions, which improved the scientific content of the publication. This publication is an NIO contribution 6037.

Edited by: A. Sterl

Reviewed by: two anonymous referees

\section{References}

Amrutha, M. M., Sanil Kumar, V., and George, J.: Observations of long-period waves in the nearshore waters of central west coast of India during the fall inter-monsoon period, Ocean Eng., 131, 244-262, doi:10.1016/j.oceaneng.2017.01.014, 2017.

Anjali, N. M. and Sanil Kumar, V.: Spectral wave climatology off Ratnagiri - northeast Arabian Sea, N. Hazards, 82, 1565-1588, 2016.

Badulin, S. I., Babanin, A. V., Zakharov, V. E., and Resio, D.: Weakly turbulent laws of wind-wave growth, J. Fluid Mech., 591, 339-378, 2007.
Cavaleri, L., Fox-Kemper, B., and Hemer, M.: Wind-waves in the coupled climate system, B. Am. Meteorol. Soc., 93, 1651-1661, 2012.

Chakrabarti, S. K.: Handbook of Offshore Engineering, in: Ocean Engineering Series, Vol. 1, Elsevier, Amsterdam, the Netherlands, p. 661, 2005.

Chen, G., Chapron, B., Ezraty, R., and Vandemark, D.: A global view of swell and wind-sea climate in the ocean by satellite altimeter and scatterometer, J. Atmos. Ocean. Tech., 19, 18491859, 2002.

Datawell: Datawell Waverider Reference Manual, Datawell BV oceanographic instruments, Haarlem, the Netherlands, 123 pp., 10 October 2009.

Donelan, M. A.: The effect of swell on the growth of wind waves, Johns Hopkins APL Technical Digest., 8, 18-23, 1987.

Donelan, M. A., Hamilton, H., and Hui, W. H.: Directional spectra of wind-generated waves, Philos. T. Roy. Soc. Lond. A, 315, 509-562, 1985.

Donelan, M. A., Curcic, M., Chen, S. S., and Magnusson, A. K.: Modeling waves and wind stress, J. Geophys. Res.-Oceans., 117, C00J23, doi:10.1029/2011JC007787, 2012.

Dora, G. U. and Sanil Kumar, V.: Sea state observation in islandsheltered nearshore zone based on in situ intermediate-water wave measurements and NCEP/CFSR wind data, Ocean Dynam., 65, 647-663, 2015.

Forristall, G. Z.: Measurements of a saturated range in ocean wave spectra, J. Geophys. Res.-Oceans, 86, 8075-8084, 1981.

Gagnaire-Renou, E., Benoit, M., and Forget, P.: Ocean wave spectrum properties as derived from quasi-exact computations of nonlinear wave-wave interactions, J. Geophys. Res.-Oceans, 115, C12058, doi:10.1029/2009JC005665, 2010.

Glejin, J., Sanil Kumar, V., Sajiv, P. C., Singh, J., Pednekar, P., Ashok Kumar, K., Dora, G. U., and Gowthaman, R.: Variations in swells along eastern Arabian Sea during the summer monsoon, Open J. Mar. Sci., 2, 43-50, 2012.

Glejin, J., Sanil Kumar, V., Balakrishnan Nair, T. M., and Singh, J.: Influence of winds on temporally varying short and long period gravity waves in the near shore regions of the eastern Arabian Sea, Ocean Sci., 9, 343-353, doi:10.5194/os-9-343-2013, 2013.

Glejin, J., Sanil Kumar, V., Amrutha, M. M., and Singh, J.: Characteristics of long-period swells measured in the in the near shore regions of eastern Arabian Sea, Int. J. Nav. Arch. Ocean Eng., 8, 312-319, 2016.

Gunson, J. and Symonds, G.: Spectral Evolution of Nearshore Wave Energy during a Sea-Breeze Cycle, J. Phys. Oceanogr., 44, 31953208, 2014.

Harish, C. M. and Baba, M.: On spectral and statistical characteristics of shallow water waves, Ocean Eng., 13, 239-248, 1986.

Hasselmann, K., Barnett, T. P., Bouws, F., Carlson, H., Cartwright, D. E., Enke, K., Ewing, J. A., Gienapp, H., Hasselmann, D. E., Krusemann, P., Meerburg, A., Muller, P., Olbers, D. J., Richter, K., Sell, W., and Walden, H.: Measurements of windwave growth and swell decay during the Joint North Sea Wave Project (JONSWAP), Deutches Hydrographisches Institut, A8, 1-95, 1973.

Hwang, P. A., Garcia-Nava, H., and Ocampo-Torres, F. J.: Dimensionally Consistent Similarity Relation of Ocean Surface Friction Coefficient in Mixed Seas, J. Phys. Oceanogr., 41, 1227-1238, 2011. 
Kahma, K. K.: A study of the growth of the wave spectrum with fetch, J. Phys. Oceanogr., 11, 1503-1515, 1981.

Kalnay, E., Kanamitsu, M., Kistler, R., Collins, W., Deaven, D., Gandin, L., Iredell, M., Saha, S., White, G., Woollen, J., and Zhu, Y.: The NCEP/NCAR 40-year reanalysis project, B. Am. Meteorol. Soc., 77, 437-471, doi:10.1175/15200477(1996)077<0437:TNYRP>2.0.CO;2, 1996.

Kawai, S., Okada, K., and Toba, Y.: Field data support of threeseconds power law andgu* $\sigma-4$-spectral form for growing wind waves, J. Oceanogr., 33, 137-150, 1977.

Kitaigordskii, S. A., Krasitskii, V. P. and Zaslavskii, M. M.: On Phillips' theory of equilibrium range in the spectra of windgenerated gravity waves, J. Phys. Oceanogr., 5, 410-420, 1975.

Kuik, A. J., Vledder, G., and Holthuijsen, L. H.: A method for the routine analysis of pitch and roll buoy wave data, J. Phys. Oceanogr., 18, 1020-1034, 1988.

Liu, A. K., Jackson, F. C., Walsh, E. J., and Peng, C. Y.: A case study of wave-current interaction near an oceanic front, J. Geophys. Res.-Oceans, 94, 16189-16200, 1989.

Long, C. E. and Resio, D. T.: Wind wave spectral observations in currituck sound, north Carolina, J. Geophys. Res.-Oceans, 112, C05001, doi:10.1029/2006JC003835, 2007.

Melville, W. K.: Energy dissipation by breaking waves, J. Phys. Oceanogr., 24, 2041-2049, 1994.

Neetu, S., Satish, S., and Chandramohan, P.: Impact of sea breeze on wind-seas off Goa, west coast of India, J. Earth Syst. Sci., 115, 229-234, 2006.

Phillips, O. M.: Spectral and statistical properties of the equilibrium range in wind-generated waves, J. Fluid Mech., 156, 505-531, 1985.

Pierson, W. J. and Moskowitz, L.: A proposed form for fully developed seas based on the similarity theory of S. A. Kitaigorodski, J. Geophys. Res.-Oceans, 69, 5181-5190, 1964.

Portilla, J., Ocampo-Torres, F. J., and Monbaliu, J.: Spectral Partitioning and Identification of Wind-sea and Swell, J. Atmos. Ocean. Tech., 26, 117-122, 2009.

Ranjha, R., Tjernström, M., Semedo, A., and Svensson, G.: Structure and variability of the Oman Coastal Low-Level Jet, Tellus A, 67, 25285, doi:10.3402/tellusa.v67.25285, 2015.

Rao, C. P. and Baba, M.: Observed wave characteristics during growth and decay: a case study, Cont. Shelf Res., 16, 1509-1520, 1996.

Sanilkumar, V., Ashokkumar, K., and Raju, N. S. N.: Wave characteristics off Visakhapatnam coast during a cyclone, Current Science, 86, 1524-1529, 2004.
Sanil Kumar, V. and Anand, N. M.: Variation in wave direction estimated using first and second order Fourier coefficients, Ocean Eng., 31, 2105-2119, 2004.

Sanil Kumar, V. and Anjali Nair, M.: Inter-annual variations in wave spectral characteristics at a location off the central west coast of India, Ann. Geophys., 33, 159-167, doi:10.5194/angeo-33-1592015, 2015.

Sanil Kumar, V., Anand, N. M., Kumar, K. A., and Mandal, S.: Multipeakedness and groupiness of shallow water waves along Indian coast, J. Coast. Res., 19, 1052-1065, 2003.

Sanil Kumar, V., Johnson, G., Dora, G. U., Chempalayil, S. P., Singh, J., and Pednekar, P.: Variations in nearshore waves along Karnataka, west coast of India, J. Earth Syst. Sci., 121, 393-403, 2012.

Sanil Kumar, V., Shanas, P. R., and Dubhashi, K. K.: Shallow water wave spectral characteristics along the eastern Arabian Sea, Nat. Hazards, 70, 377-394, 2014.

Semedo, A., Sušelj, K., Rutgersson, A., and Sterl, A.: A global view on the wind-sea and swell climate and variability from ERA-40, J. Climate, 24, 1461-1479, 2011.

Shetye, S. R., Shenoi, S. S. C., Antony, A. K., and Kumar, V. K.: Monthly-mean wind stress along the coast of the north Indian Ocean, J. Earth Syst. Sci., 94, 129-137, doi:10.1007/BF02871945, 1985.

Siadatmousavi, S. M., Jose, F., and Stone, G. W.: On the importance of high frequency tail in third generation wave models, Coast. Eng., 60, 248-260, 2012.

Toba, Y.: Local balance in the air-sea boundary processes, J. Oceanogr., 29, 209-220, 1973.

Toffoli, A., Onorato, M., and Monbaliu, J.: Wave statistics in unimodal and bimodal seas from a second-order model, Eur. J. Mech. Fluids B, 25, 649-661, 2006.

Torsethaugen, K. and Haver, S.: Simplified double peak spectral model for ocean waves, in: Proceeding of the 14th International Offshore and Polar Engineering Conference, 23-28 May 2004, Toulon, France, 2004.

Vethamony, P., Rashmi, R., Samiksha, S. V., and Aboobacker, M.: Recent Studies on Wind Seas and Swells in the Indian Ocean: A Review, Int. J. Ocean Clim. Syst., 4, 63-73, 2013.

Young, I. R. and Babanin, A. V.: Spectral distribution of energy dissipation of wind-generated waves due to dominant wave breaking, J. Phys. Oceanogr., 36, 376-394, 2006.

Yuan, Y. and Huang, N. E.: A reappraisal of ocean wave studies, J. Geophys. Res.-Oceans., 117, C00J27, doi:10.1029/2011JC007768, 2012. 